\title{
Research on performance of polyester fiber and SBR latex
}

\section{compound-modified cement mortar}

\author{
Jing Zhu \\ Hubei Communications Technical College, Wuhan, Hubei, 430074, P.R China \\ xbb1220@qq.com
}

Key words: SBR latex; polyester fiber; mortar; rheological properties

Abstract: For effectively dealing with the low flexural strength, high brittleness of ordinary mortar, this article proposed a new design method of compound-modified mortar with the inclusion of polyester fiber and styrene-butadiene rubber Latex (SBR latex). The results revealed that the addition of SBR latex had positive effect on fluidity, rheological property and impermeability. The viscosity showed a trend of decrease at high polymer content. The compressive and flexural strength could be slightly improved with the addition of polyester fiber, the optimal fiber content tend to be 0.1 vol. $\%$.

\section{Introduction}

Cement mortar as an widely used building materials has been applied to plastering, repairing, waterproofing, grouting, and so on, which requiring excellent performance at workability, mechanics and durability. However, ordinary mortar have some disadvantages such as low flexural strength, high brittleness and drying shrinkage, weak impermeability, etc [1,2]. Fortunately, with the polymeric materials science and in-depth insights of the correlations and causations between material structures and properties progressing, it is noted that polymer has been implemented or gradually applied to cement-based materials field currently. Large quantities of excellent properties possessed by polymer, such as waterproof, filling, flocculation and thickening effects were discovered $[3,4]$.

Nevertheless, two major challenges constantly deteriorate the durability of polymer modified cement mortar. Initially, since polymer possesses large coefficient of linear expansion, the substrate of mortar is prone to develop micro-cracks due to chemical and drying shrinkage. In addition, the elastic modulus of polymer and cement stone vary widely so that the interface of substrate between them is as well inclined to form large fatigue cracks.

At the same time, organic fibers as an alternative building material have been used as it can strengthen the crack resistance and the toughness of the cement-based materials effectively, and it is capable of reinforcing the impermeability and effectively eliminating the stress concentration of cement-based materials as well. However, Inside fiber reinforced mortar, especially in the interface transition zone (ITZ) between fiber and cement substrate, there tend to be a large quantity of harmful pores, giving rise to the weak bonding among cement hydrates, fibers and aggregates.

On the basis of the above situation and to solve these problems, some researchers have conducted a series of tests and theory studies. A new design idea that is organic fiber and polymer modified cement mortar which have been put forwarded through their explorations. Based on the above ideas, we proposed a new design method that using polyester fiber and styrene-butadiene rubber latex (SBR latex) to fabricate compound-modified cement mortar. In this article, we try to conduct several tests to attest the superiorities of this new compound modified cement mortar at 
workability, mechanical properties, compared with ordinary and single modified cement mortar.

\section{Experimental procedures}

\section{Materials}

The materials used in this research were: Ordinary Portland cement comparable to ASTM Type I $\left(42.5 \mathrm{~N} / \mathrm{mm}^{2}\right)$ was used. The sand was ISO 679 standard sand. $6 \mathrm{~mm}$ long polyester fiber was adopted. The polymer used was a kind of SBR latex. The water used conformed to ASTM C94. In order to ensure the similar fluidity (target flow is $150 \mathrm{~mm}$ ) of sample in mechanical test, the content of the water reducer varied from 0 to $1.5 \% \mathrm{wt} . \%$. The water reducer is polycarboxylic acid type conformed to ASTM C494 type F.

\section{Test method}

(1) Rheological properties test

The rheological behavior was tested by brookfield R/S Plus rotary rheometer. Under this condition, flow curves were defined according to the Bingham model.

(2) Compressive, flexural strength and flexural toughness performance test

The specimens were cast in three lifts, and the dimensions of the specimens for compressive strength, flexural strength and flexural toughness tests was $40 \times 40 \times 160 \mathrm{~mm}$. The mortar specimens with no addition of SBR latex demolded after $24 \mathrm{~h}$ were placed in water maintained at $25 \square$, and the polymer-modified mortar specimens were covered with plastic film after demolding, then cured by watering. The compressive and flexural strength test was conducted according to ASTM C109 and ASTM C348-97 when the specimens were cured for 7d, 28d and 90d.

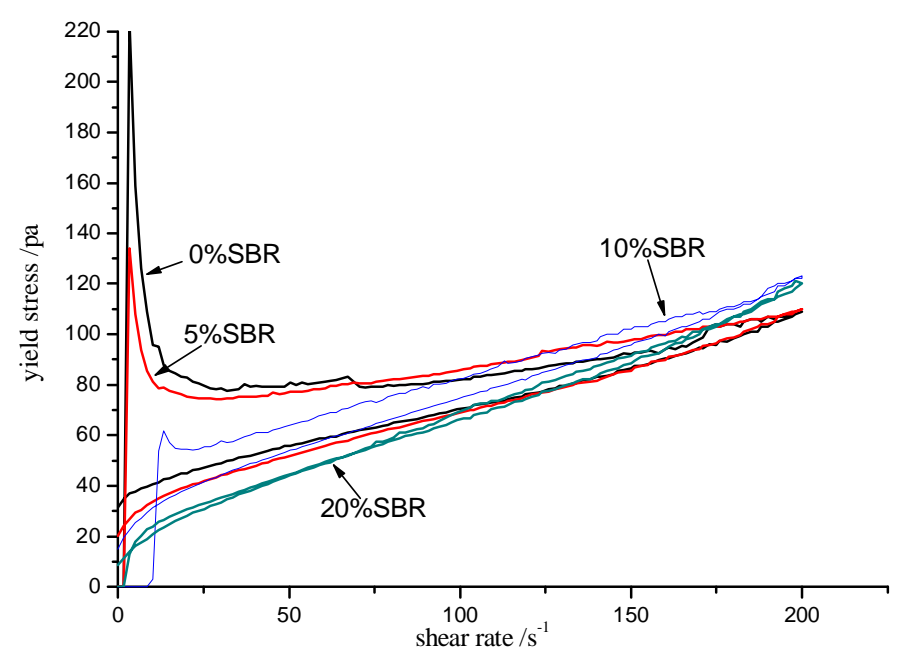

Figure 1 The influence of SBR latex dosage on the rheological properties 


\section{Results and discussion}

\section{Influence of SBR latex on the rheological property of cement paste}

The effects of SBR latex on the rheological property of cement paste were revealed in Fig.1. At the first increase stage of shearing rate, the viscosity of cement paste declined by a certain extent with the content of SBR latex increasing, but the lowered range was not obvious. Nevertheless, At the second decrease stage of shearing rate, the effect of SBR latex on the viscosity of cement paste became more evident. Compared to the ordinary cement paste, the viscosity of the cement paste mixed with SBR latex was more lower. It could be concluded that the addition of SBR latex made the rheological property of cement paste get apparent improvement. The test results also indicated the improvement effect tending to be evident with the SBR latex dosage increased.

Mechanical properties evaluation

\section{Influence of polyester fiber and SBR latex on the compressive and flexural strength of cement mortar}

The effects of polyester fiber and SBR latex on the strength properties of modified mortar were revealed in table1, Fig. 2 and Fig.3. In each specimen, the content of polyester fiber was fixed to 0.1 vol \%, the polymer-cement ratio was selected at $5,10,15$ and $20 \%$ separately.

Table1 The influence of polyester fiber content on the compressive and flexural strength of cement mortar

\begin{tabular}{|c|c|c|c|c|c|c|c|}
\hline \multirow[t]{2}{*}{$\begin{array}{l}\text { Fiber } \\
(\operatorname{vol} \%)\end{array}$} & \multirow[t]{2}{*}{$\begin{array}{l}\mathrm{P} / \mathrm{C} \\
(\%)\end{array}$} & \multicolumn{2}{|c|}{$\begin{array}{l}\text { compressive strength } \\
\sigma_{c}(\mathrm{MPa})\end{array}$} & \multicolumn{2}{|c|}{$\begin{array}{l}\text { Flexural strength } \\
\sigma_{f}(\mathrm{MPa})\end{array}$} & \multicolumn{2}{|c|}{$\begin{array}{l}\text { bend-press ratio } \\
\sigma_{f} / \sigma_{c}\end{array}$} \\
\hline & & $7 d$ & $28 \mathrm{~d}$ & $7 d$ & $28 \mathrm{~d}$ & $7 d$ & $28 \mathrm{~d}$ \\
\hline 0 & 0 & 51.4 & 54.5 & 7.39 & 8.03 & 0.144 & 0.147 \\
\hline $0.05 \%$ & 0 & 52.2 & 54.7 & 7.58 & 8.11 & 0.145 & 0.148 \\
\hline $0.10 \%$ & 0 & 52.6 & 56.5 & 7.75 & 8.39 & 0.147 & 0.148 \\
\hline $0.15 \%$ & 0 & 51.7 & 53.5 & 7.57 & 8.26 & 0.146 & 0.154 \\
\hline
\end{tabular}

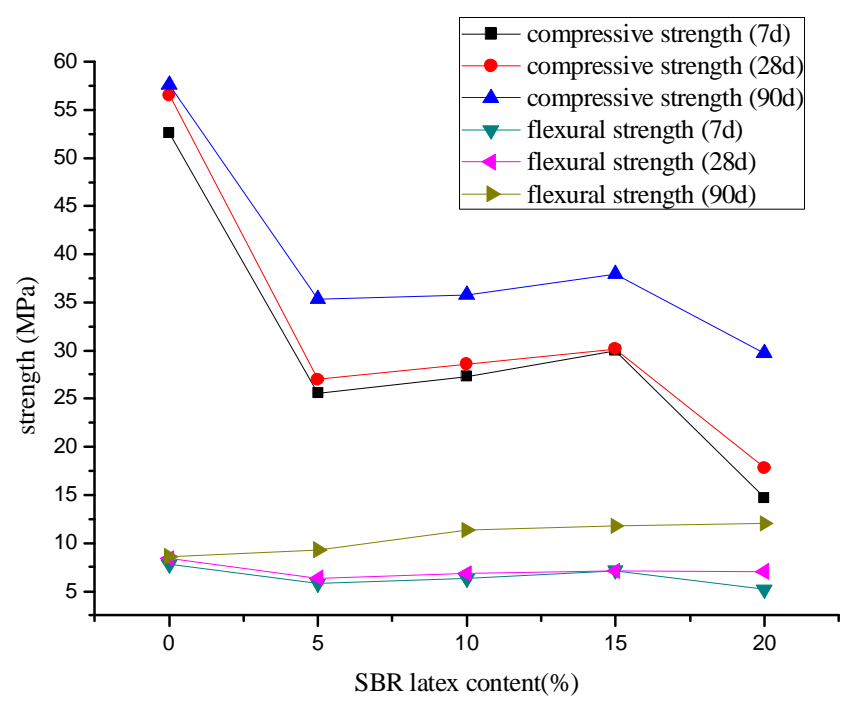

Figure 2 the strength of modified mortar at 0.1 vol\% of polyester fiber 


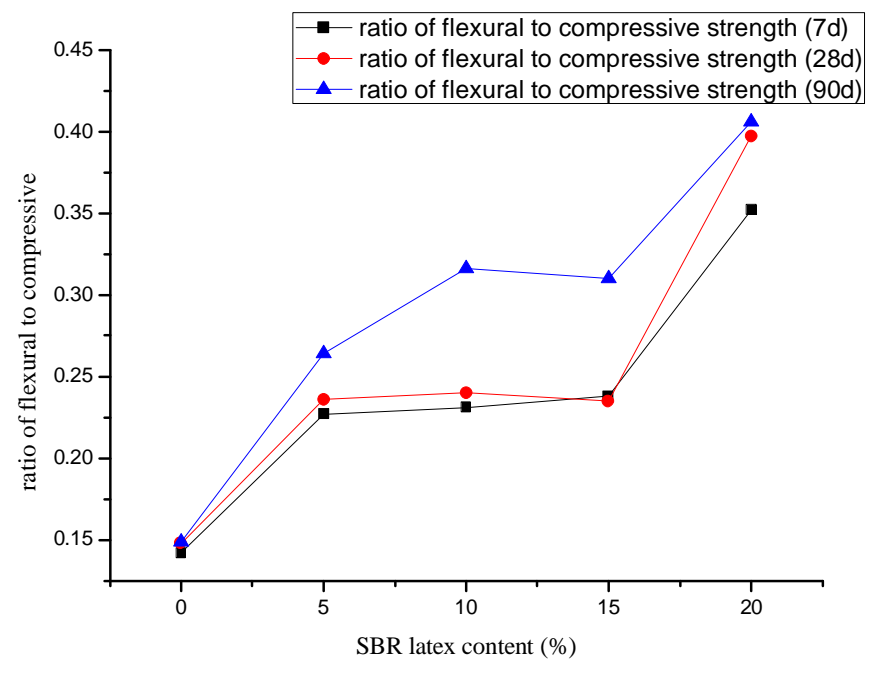

Figure 3 the ratio of flexural to compressive strength of modified mortar at 0.1 vol $\%$ of fiber

As for compressive strength of mortar modified with polymer, they all showed descends no matter the curing time was $7 \mathrm{~d}, 28 \mathrm{~d}$ or $90 \mathrm{~d}$. Especially, when the polymer-cement ratio increased to $20 \%$, the decline rates of compressive strength at different curing time (7d, 28d, 90d )were $73.1 \%$, $68.5 \%$ and $48.4 \%$. It illustrated the excessive addition of polymer will make the compressive strength diminished dramatically. However, although the compressive strength declined to a certain degree when mixed with $5 \%$ polymer-cement ratio, whereafter, it showed a slightly increase with the content of SBR latex rose and reached to maximum at $15 \%$ polymer-cement ratio. Moreover, with the curing time prolonged, the compressive strength increased.

With respect to the flexural strength, the early flexural strength $(7 \mathrm{~d}, 28 \mathrm{~d})$ of modified mortar declined to a certain degree and it was not apparent for different polymer dosage. But the test results of specimens cured for $90 \mathrm{~d}$ showed that the flexural strength enhanced greatly with the addition of polymer, and as the content of SBR latex rose, the flexural strength grew correspondingly.

Based on the result of the above analysis, we could confirm the following mechanical properties of the modified cement mortar: with the addition of polymer, the flexural strength increased but the compressive strength confront a drastic reduction, that resulted in the growth of the ratio of flexural to compressive strength which showed that the flexibility of the modified mortar mixed with polyester fiber and SBR latex reinforced.

\section{The compound-modified mechanism of polyester fiber and SBR latex}

According to the previous studies, in polymer-modified mortar, aggregates are bound by such a network structure in which the cement hydrate phase and polymer phase interpenetrate, resulting in superior properties compared with conventional composites. The setting of polymer-modified mortar is delayed to some extent compared with ordinary cement mortar depended on the polymer type and polymer-cement ratio. The interfacial transition zone (ITZ) between the cement paste and aggregates particles improved by the additions of fiber and polymer.

\section{Conclusions}

(1) SBR latex has positive effects on the workability of cement mortar, with the increase of polymer content, the water water-reducing ratio get larger. The viscosity showed a trend of decrease at high polymer content.

(2) The compressive and flexural strength could be slightly improved with the addition of polyester fiber, the optimal fiber content tend to be 0.1 vol.\%. With the addition of SBR latex, the 
compressive strength showed a certain extent decrease, but the flexural strength enhanced, and the increase ratio depends on the content of SBR latex and the curing time. the optimal polymer-cement ratio tend to be $15 \%$.

(3) In polymer-modified mortar, aggregates are bound by such a network structure in which the cement hydrate phase and polymer phase interpenetrate, resulting in superior properties compared with conventional composites.

\section{Acknowledgements}

This work was supported by the Research Funds of Hubei Communications Technical College (201515).

\section{Reference}

[1] Banthia N, Yan C. Shrinkage cracking in polyolefin fiber-reinforced concrete. ACI Mater. J. 2000; 97: 432-37.

[2] Cao ML, Zhang C, Lv HF, Xu L. Characterization of mechanical behavior and mechanism of calcium carbonate whisker-reinforced cement mortar. Constr. Build. Mater. 2014; 66: 89-97.

[3] Zhong, S.; Yuan, H. Application of polymer in concrete. Chemistry Industry Press: Beijing, 2003.

[4] Ohama Y. Recent research and development activities of polymer-modified mortar and concrete in Japan. In Proceedings of the third Asia symposium on polymer in concrete, Shanghai, Nov 20-3, 2000. 